\title{
The rise of tech giants in the fund sales industry: an example of how information and digital technology rebuild platform economy
}

\author{
Bowen Jiang ${ }^{1}$ \\ ${ }^{1}$ Olin business school, Washington University in St.Louis,MO,63130,USA
}

\begin{abstract}
Unlike its American counterpart, the Chinese financial industry has been challenged by tech giants through their digital platforms. As the entrance of the asset management industry, the fund sales industry is at the center of the revolution, with commercial banks and tech giants fighting for its control. Some scholars have discussed the competition, but none of them discussed the competition by comparing their common features as platforms. Moreover, the competition is in a two-sided multihoming market that has long been ignored by scholars but will prevail in the future. With similar coverage rates for both fund managers and investors, how do fintechs use information and digital technology gobbling a big chunk of commercial banks' profit. This article filled the gap by examining the common features of commercial banks and tech giants as platforms, including membership externality, usage externality, and multihoming behavior. Usage externality is crucial in this competition. It promoted market efficiency by unlocking the scale effect and using big data analysis. However, unlike the competition between other platforms, membership externality has little impact on the competition among commercial banks and tech giants. With prevailing multihoming behaviors to a high degree, newly entered platforms provided almost no additional membership externality.
\end{abstract}

\section{Introduction}

From the day the financial institution was born, the "blood of platform" runs in its vein. Even money itself is a platform used to coordinate the demands of different people. With the money comes the wealth and asset management. Before 2013, the wealth of the Chinese family has long been concentrated on non-financial assets. The entering of tech giants changed this scenario. From 2013 to 2020, the proportion of financial assets has maintained an upward trend, with growth by around $10 \%$, from $41 \%$ to $51 \%$ ( Ant Group Research Institution \& Renmin University Fintech Researcher Institution, 2020).

The fund sales industry is at the center of this revolution. Unlike its United States counterparts, which brought an industry evolvement within and reinforced the position of incumbent companies ( Haberlya, MacDonald-Korthb, Urbanb, Wójcikb, 2019), the traditional sales channel, commercial bank, has been disrupted by newly entered tech giants.
In China, both commercial banks and tech giants act as the typical two-sided market platform defined by Armstrong (2006) and Rochet \& Tirole (2003). They share all the typical features, including membership and usage externality, Nonneutral pricing, and multihoming behavior with other two-sided market platforms. However, for all researches related to the revolution in the fund sales industry, there is no systematic analysis base on the examination of the common features of platforms. Haberlya, MacDonald-Korthb, Urbanb and Wójcikb (2019) have discussed the evolution of the asset management industry from the economic geographic standpoint. Wang (2016) has discussed the Chinese fund sales industry from the pricing structure perspective. More importantly, the competition among the two types of platforms is a competition in a two-sided multihoming market, which scholars have long ignored. The traditional view is that if each member of a group joins all platforms, there is no need for any member of another group to join more than one platform. (Armstrong, 2006). However, with platforms that have huge customer bases crossing over their 
original business boundaries, the competition in two-sided multihoming markets will prevail.

Here the gap was filled by examining the common features shared by two-sided market platforms and explaining their competition by their common features. As the article will show, (1), multihoming behavior is common both on the investors and the fund companies. Thus, (2) it is a competition in a two-sided multihoming market that the entering of the new platform provides no additional membership externality for both sides of the market. (3) Tech giants beat commercial banks by providing usage externality. Specifically, it unlocks the benefit of scale effect by avoiding benefit conflict between fund companies and commercial banks, further reduced the cost and promote efficiency by using big data analysis.

\section{Platform and platform economics}

Platform was initially used by a scholar to descript a new method of product development. (Wheelwright \& Clark, 1992). With the expansion of its adoption, scholars have used the word "platform" in different areas, especially product development and industry economics. Although the definition of platform varies due to the many perspectives of different scholars, there are some common features of "platforms" across different research areas. As noticed by Baldwin \& Woodard (2008), a platform is a set of stable components that support variety and evolvability in a system by constraining the linkage among the other components. Generally speaking, platform is the combination of the reusable and stable components of a system and the rule that govern the allocation of these components. Take the platform in the software industry as an example; Operating system provides the interface and various reusable fundamental components that can be invoked by various software to implement different functions. Computer games, mathematical programs, and Internet browsers share the same components provided by the operating systems and governed by its rules. As for platforms in the asset management industry, they fit into the research area of platform economics.

\subsection{The definition and common features of Platform in platform economics}

Sharing the common feature of all platforms, Platforms in platform economics is also the rule and the stable components of a system whose main function is the coordination of demands of different ender users. Under most circumstances, such platforms are dealing with two distinct user groups such as buyers and sellers, developers and game players, drivers and passengers. Thus, platform economics is industrial economics focused on the theories of two-sided markets. Due to platforms' complexity, scholars redefined platform in platform economics to make their research area clear.

A widely accepted definition of the two-sided market platform is created by Armstrong and Rochet \& Tirole through two constraint conditions: cross-group externality and Nonneutral pricing. Cross-group externality exists when the benefit enjoyed by a member of one group depends upon how well the platform does in attracting custom from the other group(Armstrong, 2006). Crossgroup externality is also called membership externality. Its conception derives from the membership fees charged by the platform and is independent of the usage of the platform. Take the telecommunication industry as an example; some companies may charge a fixed fee for creating a new account, whether it be used or not. Thus, the membership externality derives from the potential to interact with other end users.

Besides cross-groups externality, Roche \& Tirole (2003) added the Nonneutral pricing constraint. A market with network externality is a two-sided market if the platform can effectively cross-subsidize between different categories of endusers that are parties to a transaction. Under their definition, price structure is a vital feature of a platform, which indicates that a platform should be able to provide externality, allocate the total price between different end-users, and adjust the platform's benefit along with the volume of transactions. Cross-subsidize is prevailing under current platform competition. A perfect example is Uber. It gives out coupons when it tries to attract passengers and raises the price during rush hours or under inclement weather to attract more drivers.

In addition to the two restricted conditions, Platforms under the platform economics have two common features: usage externality and multihoming. As noticed by Roche \& Tirole (2004), the externality between end users can be further separated into membership externality and usage externality. Membership externality has been mentioned in the last paragraph. Usage externality, on the other hand, is strictly bound with the usage of the platform. It usually has a proportional relationship with the use of the platform. For example, Uber and the payment institution will charge variable fees based on the order, specifically, the time and distance of different journeys or the 
order's transaction amount. Overall, the distinguish between membership externality and usage externality can help us identify the value drivers of varying platforms and understand the competition strategies adopted by different platforms.

Multihoming is crucial since it is one of the most critical factors that affect pricing strategies among different platforms. The definition of multihoming is straight forward. Users rely contemporaneously on more than one platform for a side (Evans, 2003). Multihoming varies in different industries. For example, it is rare for a computer user to use two operating systems but prevailing for buyers to shop on different shopping platforms. Multihoming behaviors among different users will cause platforms to adjust their pricing strategy; however, although multihoming is important to platforms' pricing strategies, surprisingly little work studies the competitive effects of multihoming. The widely accepted view about multihoming's impact on pricing strategy is that in the situation that one group single-homes while the other multi-homes, the platform tends to exert monopoly power over the other sides. Under such circumstances, platforms are likely to charge a higher price for the multihoming side and use the high profits to subsidize the single-homing side (Armstrong, 2006).

\subsection{The typical development pattern of Platforms in platform economics}

A typical platform promotes market efficiency and develops itself by providing externalities. Firstly, the membership externality provides by its network feature will attract more users, further increasing its membership externality. Secondly, the usage externality typically comes from the scale effect of economy. Due to its reusable and stable feature, platform usually has a much lower marginal cost that will decrease with the increase of its users. Thus, it is easy for the platform to gain from conventional scale economies and hence provide usage externality for the users. All in all, the membership externality and reusable feature of the platform create a snowball effect for the platform and a trend toward concentration at the platform provider level (Economist, 2018c)

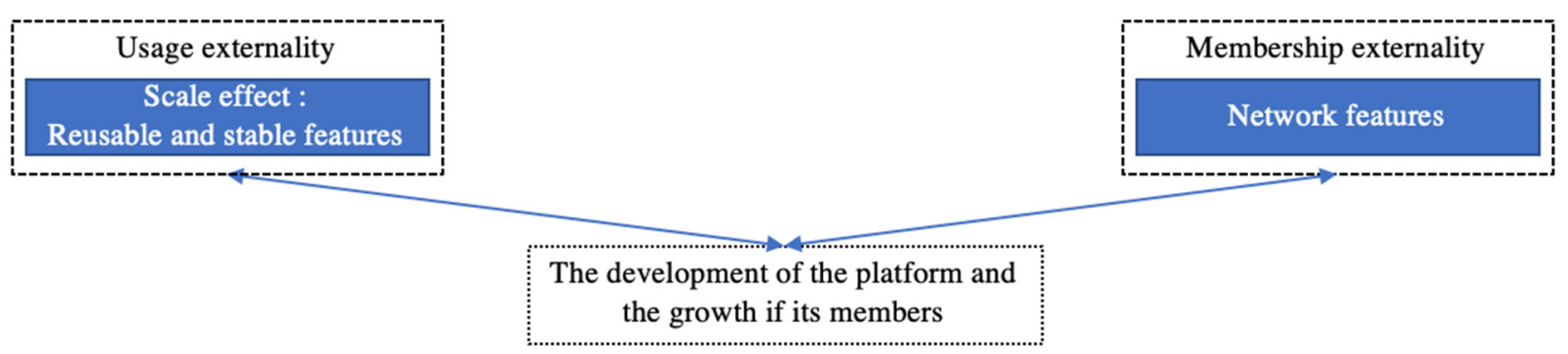

Figure 1. The development pattern of platforms in platforms economics

Source: Draw by author

\section{Platform economics in the fund sales industry}

In China, Open-ended funds have long relied on platforms to sell its product, traditionally, through Commercial banks. In 2013, Commercial banks accounted for $58 \%$ of the total funds' sales. However, with the development of Chinese technology giants, commercial banks' position as fund sales platforms has been weakened. More seriously, the tech giants' efforts in asset management even affected commercial banks' deposit business. As noticed by Li \& Xu (2014), due to the entering of tech giants, the share of core deposits-non interbank deposit- in total deposits has been declining since 2013 for most commercial banks in China. Meanwhile, launched in 2013, Alibaba-owned Yu'E Bao became the world's biggest money market fund in 2017, with $\$ 165 \mathrm{bn}$ under management ( Financial Time, 2017).

\subsection{The two types of platform in the fund sales industry}

The competition of two types of platforms in the fund sales industry is a unique phenomenon in China. Although there were predictions that the incumbent financial giants would be supplanted by Fintech start-ups (Arner et al, 2016), the technological revolution in the wealth and asset management industry was actually brought by financial giants in most other countries. As a result, the position of incumbent financial giants outside China has been reinforced (Haberlya, MacDonaldKorthb, Urbanb, Wójcikb., 2019).

Unlike the wealth management industry in western countries, the wealth and asset management industry in China is still on the inchoate stage and 
cannot rely on self-owned sales channels. Besides this, China's household savings rate is stubbornly high, which means asset management is a rigid demand in China. Due to the two factors above, fund sales platforms are common in China. Commercial banks are the traditional sales channels. Before the entering of the tech giants, commercial banks account for $58 \%$ of the total sales, more than the combination of other sales channels. Tech giants started to enter the industry in 2013, starting by Alibaba's sale of the Yu'E Bao. The typical tech giants are BATD, which are Baidu, Alibaba, Tencent, and JD. All of these companies have a monopoly or leading position in specific areas in China, along with a huge customer base.

Since tech giants entering the industry, the shares of commercial banks have decreased at a startling speed. According to the data of the asset management association of China, commercial banks' shares in the fund sales industry dropped by $35.61 \%$, from $58.41 \%$ in 2013 to $22.80 \%$ in 2018 . On the other hand, tech giants are doing well in the fund sales industry. Although the exact share of tech giants is still unknown, tech giants' success is obvious. Owned by Alibaba, Yu'E Bao is now the biggest money fund in the world.

\subsection{Comparison of the common features of the two types of platform}

Table 1. Number of users for commercial banks and tech giants in 2013

\begin{tabular}{|c|c|c|c|}
\hline Alipay & WeChat & ICBC $^{\mathrm{a}}$ & CCB $^{\mathrm{b}}$ \\
\hline over 300 Million & over 400 Million & 431 Million & 291Million \\
\hline
\end{tabular}
${ }^{\mathrm{a}}$ Industrial and Commercial Bank of China
${ }^{\mathrm{b}}$ China Construction Bank
Source: Public information and banks' annual report

Secondly, the two types of platforms are both attractive to fund companies. Commercial banks were the largest sales channel for public funds when tech giants got into this industry. In 2011, Ping An Bank, China Merchants Bank, and China Construction Bank ranked the top three in terms of the number of consigned funds. With 1,034, 977, and 918 consigned funds, the three banks covered $92 \%, 87 \%$, and $82 \%$ of the total amount of mutual funds, respectively. (Chinafund, 2020). However,
A simple analysis will reveal that commercial banks and tech giants both fit into the definition of platform. They act as the matchmaker between investors and fund managers in the fund sales industry. Meanwhile, both of them can crosssubsidize between fund managers and investors to adjust transaction volume and platform profit. Specifically, commercial banks and network asset management platforms cross-subsidize by adjusting the fund management fee. Thus, it is reasonable to analyze their competition based on the two-sided market platforms' common features.

\subsubsection{Comparison of the membership externality}

Surprisingly, Membership externality seems unimportant in the competition between commercial banks and tech giants. Firstly, both commercial banks and tech giants have tremendous customer bases. Launched its first asset management product $\mathrm{Yu}^{\prime} \mathrm{E}$ Bao in 2013, Alibaba already had more than 300 million customers. A year later, Tencent launched its first asset management product on WeChat, which had more than 500 million users. Meanwhile, China's two largest commercial Banks, Industrial and Commercial Bank of China (ICBC) and China Construction Bank (CCB), had 450 million and 400 million individual customers, respectively, in 2013.

facing more than 300 million customer bases, fund companies are enthusiastic about the tech giants' sales channels. Two months later after YU'E Bao was launched, more than half of the fund companies were trying to sell their funds on Alibaba's Platform Alipay and TaoBao (Securities Times, 2013). After seven years of development, more than 5000 funds are selling on the Alipay, covering 90 percent of China's open-ended funds.

Table 2. Number of funds sold on commercial banks in Dec 2013

\begin{tabular}{|c|l|c|c|}
\hline $\mathrm{ABC}^{\mathrm{a}}$ & $\mathrm{BOC}^{\mathrm{b}}$ & $\mathrm{ICBC}$ & $\mathrm{CCB}$ \\
\hline 1090 & 949 & 1054 & 1103 \\
\hline
\end{tabular}

${ }^{\mathrm{a}}$ Agricultural Bank of China

Source: Public information and banks' annual report 
Thirdly, the prevailing multihoming behavior on both sides of the market makes the fund sales industry a two-sided multihoming market. As we have mentioned in the last paragraph, multihoming behavior prevails among fund companies, with more than $80 \%$ of the companies selling their product through multiple channels. Meanwhile, each customer of tech giants must have at least one bank account to complete the transfer, which means commercial banks covered almost all the users of tech giants. Taken as a whole, the entering of tech giants provided no or just a little additional externality in terms of the number of members on both sides. Thus, tech giants did not compete with commercial banks by providing membership externality to either side.

\subsubsection{Comparison of the usage externality}

Without no difference in membership externality, usage externality is the main difference between the two types of platforms. Surprisingly, the typical usage externality provided by scale effect was internality by commercial banks by its monopoly position before tech giants entering the market. Thus, tech giants compete with commercial banks by unlocking the benefit of scale effect. More than this, tech giants provided additional usage externality by big data analysis.
Firstly, tech giants unlocked the usage externality provided by the scale effect. It is easy to notice the massive transaction cost gap between tech giants and commercial banks. As discussed by ZengWu Wang (2016), before network funds sales platforms entering the market, The channel expense for open-ended funds is sky-high. Taking the equity investment product as an example, according to a rough estimation, the minimum income of commercial Banks for a deal is about $2.79 \%$ of the sales amount, which is much higher than the fund companies' management fee of $1.5 \%$. More than that, there is an additional "customer maintenance fee" for fund companies; that is, fund companies need to "share" part of their management fee with commercial Banks. The tribute rate adopts a "case to case" system, which can be as low as $20 \%$ or as high as $60 \% \sim 65 \%$. Taking the lower limit as an example, it is estimated that commercial Banks get a total income of $3.09 \%$, which is more than 1.6 times of fund companies' $1.2 \%$ income. Even under the competition of tech giants, the subscription fee of commercial banks is still much higher than that of network sales platforms. According to the official website of the biggest four commercial banks, the discount they provide during 2020 will be no more than $30 \%$. Meanwhile, tech giants such as Alipay, JD Finance provide a $90 \%$ discount for the subscription fee.

Table 3. The discount of subscription fee provided by different sales channel on Oct 10, 2020

\begin{tabular}{|c|c|c|c|c|c|c|}
\hline ABC & BOC & ICBC & CCB & WeChat & Alipay & JD Finance \\
\hline $30 \% / 50 \%{ }^{\mathrm{a}}$ & $20 \% / 40 \%{ }^{\mathrm{b}}$ & $20 \%$ & $30 \%$ & $90 \%$ & $90 \%$ & $90 \%$ \\
\hline
\end{tabular}
${ }^{\mathrm{a}} 50 \%$ off for automatic investment plan
b $40 \%$ off for automatic investment plan or purchase through the mobile bank
Source: Official Website of all the companies in the table.

The reason behind the sky-high subscription fee is a conflict between commercial banks and fund companies. According to Alipay's annual report 2014, Yu'E Bao users are concentrated around 23 years old, mainly students and young people newly employed. This group of clients are low-value customers for traditional commercial banks. The traditional way for commercial banks to sell funds was through their client managers. Thus, it is unworthy for them to spend more than half an hour and go through all the processes to get an investment of fewer than 1000 dollars. Meanwhile, low-value customers are the primary source of the core deposit of commercial banks. This group of clients' interest is much lower than the interest for the inter-bank deposit or the interest for high-value customers. Table 4 shows the demand deposit interest rate of commercial banks and the returns of money funds provided by tech giants. Thus, commercial banks had no incentive to sell openended funds to this group of customers and set a relatively high standard for open-ended fund purchases, typically with starting investment amount and redemption limitation.

Table 4. Commercial bank's Demand deposit interest rate for individual clients and the return of money fund provided by Alibaba and Tencent

\begin{tabular}{|c|c|c|c|c|c|c|}
\hline & $2013 \mathrm{Y}$ & $2014 \mathrm{Y}$ & $2015 \mathrm{Y}$ & $2016 \mathrm{Y}$ & $2017 \mathrm{Y}$ & $2018 \mathrm{Y}$ \\
\hline $\mathrm{ABC}$ & $0.36 \%$ & $0.36 \%$ & $0.36 \%$ & $0.39 \%$ & $0.41 \%$ & $0.51 \%$ \\
\hline $\mathrm{BOC}$ & $0.50 \%$ & $0.52 \%$ & $0.52 \%$ & $0.59 \%$ & $0.62 \%$ & $0.66 \%$ \\
\hline
\end{tabular}




\begin{tabular}{|c|c|c|c|c|c|c|}
\hline ICBC & $0.35 \%$ & $0.35 \%$ & $0.33 \%$ & $0.31 \%$ & $0.39 \%$ & $0.38 \%$ \\
\hline CCB & $0.36 \%$ & $0.35 \%$ & $0.34 \%$ & $0.30 \%$ & $0.30 \%$ & $0.30 \%$ \\
\hline WeChat $^{\mathrm{b}}$ & -- & -- & -- & $3.00 \%$ & $4.16 \%$ & $3.05 \%$ \\
\hline Alipay $^{\mathrm{b}}$ & $5.58 \%$ & $4.31 \%$ & $2.75 \%$ & $2.71 \%$ & $3.99 \%$ & $2.63 \%$ \\
\hline
\end{tabular}

${ }^{a}$ The annual return of Yu'E Bao at Dec 31 for each year above

${ }^{b}$ The annual return of Mini fund at Dec 31 for each year above

Source: Public information and annual reports of commercial banks

Tech giants, however, do not have such conflict with their customers. Although some of them are doing loan business, customer deposits are not allowed to be used. Without the interest conflict, tech giants unlocked usage externality provided by the scales effect and meet the demand of the socalled low-value customers by providing them with monetary funds with no minimum investment amount and no redemption limitation.

Secondly, technological provide usage externality through the use of big data technology. Individual customers do not have much interaction with commercial banks. In the typical scenarios, customers use commercial banks' services to deposit, transfer, withdraw money, or pay credit card bills. All of those are scenarios of low using frequency. The Apps of tech giants, on the other hand, have much higher interaction frequency with their customers. WeChat, Taobao, JD, Alipay are the most active Application in China. Customers use Wechat as a communication and payment tool, use TaoBao and JD to purchase items, and Alipay as a payment tool as well. Moreover, mobile payment instead of cash has become China's dominant payment method. In a no-cash society, almost all the functions of mobile bank applications, including transfer, deposit, withdraw money, or even paying the credit card bill, can be supplanted by payment applications such as Alipay and WeChat.

Table 5. Average daily active customers of different Apps in the first quarter of 2020

\begin{tabular}{|c|c|c|c|c|c|}
\hline ABC & BOC & ICBC & CCB & WeChat & Alipay \\
\hline 3.84 million & 2.93 million & 8.74 million & 6.27 million & 1151 million & $\begin{array}{c}\text { Over 231 } \\
\text { million }\end{array}$ \\
\hline
\end{tabular}

Source: Public information and Annual reports of all the companies in the table.

Thus, the tech giants are much powerful in collecting data. With higher interactive frequency, their applications can accumulate multidimensional data of the customer. The big data collected through their Apps will enable tech giants to promote precisely. With the increase of the data, tech giants' models will be more and more accurate, along with lower costs and higher efficiency.

\section{Commercial bank}

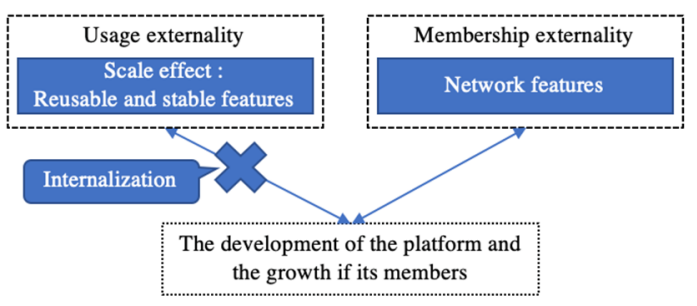

Taken as a whole, tech giants beat commercial banks by providing usage externality. Specially they unlocked the typical usage externality brought by scales effect, which comes from their reusable and stable feature as platforms. More than this, tech giants provided additional usage externality through big data analysis technology enabled by their high interactive frequency with end-users.

\section{Technological Giants}

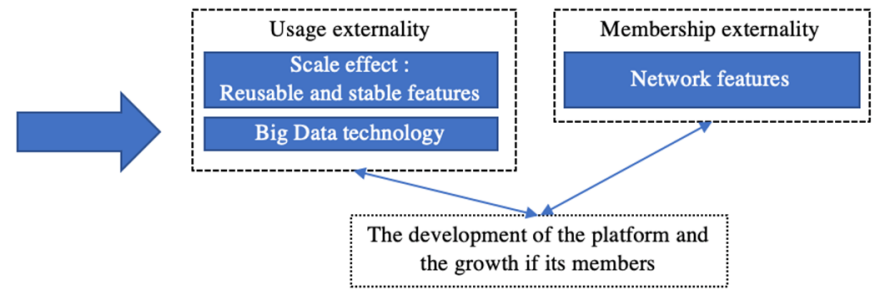

Figure 2. The difference between commercial banks and tech giants

Source: Draw by author

\section{Conclusion and Thoughts}

On Sept 25, 2020, due to their exclusive ability to involve and purchase a planned strategic placement of Shares in Ant Group's IPO, five funds have been put under the spotlight since the day they were approved. It is the first time that tech giants get exclusive sales right. Behind this is a competition between two types of platforms, commercial banks 
and tech giants. According to the data of the Asset Management Association of China, commercial banks' share in the fund sales market has dropped by $35.61 \%$ since 2013 , from $58.41 \%$ to $22.80 \%$. This article examines the competition between commercial banks and tech giants as fund sales platforms by comparing the common features shared by two-sided market platforms.

Like most two-sided market platforms, usage externality plays a crucial role in the competition between commercial banks and tech giants. It provides usage externality in the fund sales market by avoiding interest conflict and big data analysis.

Firstly, it lowers the entering barrier of funds purchase by avoiding interest conflict and providing a much lower subscription fee. The benefit conflict between the core deposit and the sales of the openended fund is an obstacle for the commercial bank to lower the subscription fee. Unless selling funds can provide an interest high than its traditional loan business, commercial banks had no incentive to do it. Without potential benefit confliction, tech giants sold funds with a much lower subscription fee.

Secondly, compared to commercial banks, tech giants interact with their end-users more frequently. The high interactive accumulated massive data for tech giants. With the massive data, tech giants built a more precise model, which can further lower the transaction costs and promote efficiency.

Unlike other two-sided platforms, membership externality is unimportant in the competition between these two types of platforms. The multihoming behavior among both fund companies and investors are surprisingly prevailing. The two types of platforms both provide investors with more than $80 \%$ of the open-end funds. Meanwhile, each tech giants user must have at least a bank account to get the deal done. With multihoming behavior to such a high degree, tech giants did not provide additional membership externality for both sides of the market.

Due to the time and material limitation, this article ignored individual differentiation inside commercial banks and tech giants. Instead, each side has been viewed as a whole that possesses some common features. To a large extent, this article is discussing the competition between twosided multihoming platforms. There is surprisingly little research in this area. The traditional view is that if each member of a group joins all platforms, there is no need for any member of another group to join more than one platform. (Armstrong, 2006). The conclusion is correct when platforms only provide single services. However, more and more platforms are trying to operate cross-boundary.
Microsoft and Google are both promoting their cloud computing service. Alipay and WeChat are competing in the mobile payment industry. With monopoly platforms trying to expand their business, two-sided multihoming behavior will become a valuable area for scholars to dive into.

\section{References}

[1] Armstrong, M. (2006) Competition in twosided markets. Rand Journal of Economics, 37: 668-691.

[2] Arner, D. W., Barberis, J., \& Buckley, R. P. (2015). The evolution of Fintech: A new postcrisis paradigm. Geo. J. Int'l L., 47:1271.

[3] Baldwin, C. Y., \& Woodard, C. J. (2009). The architecture of platforms: A unified view. Platforms, markets and innovation. Edward Elgar Publishing, $M A$, USA.

[4] CHINAFUND. (2020) Open-ended fund history | sales channel: change or not. (Chinese) https://www.sohu.com/a/397038924_465270? trans_=010001_grzy

[5] Economist. (2018) More Knock-on than Network. The Economist, Jun 30.

[6] Evans, D. S. (2003). Some empirical aspects of multi-sided platform industries. Review of Network Economics, 2(3).

[7] Financial Time. (2017) Chinese money market fund becomes world's biggest. https://www.ft.com/content/28d4e100-2a6d11e7-bc4b-5528796fe35c.

[8] Haberlya, D., MacDonald-Korthb, D., Urbanb, M., Wójcikb, D. (2019) Asset Management as a Digital Platform Industry: A Global Financial Network Perspective. Geoforum, 163: 51-59.

[9] Li D., Xu Y,. (2014). Deep Thinking of the Impact of Internet Finance on Banks. International finance, (5), 64-67. (Chinese)

[10] Remin University, Ant Group research institution. (2020) Research report on Internet Financing and consumption upgrade. https://mp.weixin.qq.com/s/C8AsYB1phunEcAQrwZZjw.

[11] Rochet, J., Tirole, J. (2003) Platform Competition in Two -sided Markets. Journal of the European Economic Association, 1(4):9901029.

[12] Wheelwright, S. C., \& Clark, K. B. (1992). Creating project plans to focus product 
development. Harvard Business School Review 70(2):70-82.

[13] Rochet, J. C., \& Tirole, J. (2004). Two-sided markets: an overview. Institut d'Economie Industrielle working paper.

[14] Securities Times.(2013) More than 40 funds rushed to enter $\mathrm{Yu}$ 'E Bao, accounting for half of the fund companies (Chinese)

https://tech.huanqiu.com/article/9CaKrnJBLin

[15] Wang, Z. (2016). Channel, wealth management and platform economy. Shanghai Finance, 4: 8-21.(Chinese) 